\title{
Win/win partnerships between Geneva health-related institutions and caregivers of people with dementia: a descriptive cross- sectional study
}

\author{
Marie-Conception Leocadie $e^{1,3,4^{*}}$ (D) , Hélène Lefebvre ${ }^{2}$ and Monique Rothan-Tondeur ${ }^{3,4}$
}

\begin{abstract}
Background: In the context of an ageing population and an increase in the appearance of chronic diseases, the commitment of caregivers makes it possible for people confronted with disease to remain at home. Over time, they need support to overcome their difficulties. They also show a need for recognition for their participation in the economic maintenance of the health system. To promote this support, so-called "win/win" partnerships are envisaged. Research is needed to identify the building blocks of an innovative intervention.

Methods: A cross-sectional descriptive study was carried out with health institutions in the canton of Geneva to identify the proportion of institutions with a positive opinion on partnership with caregivers. It has also identified potential partnerships with caregivers of people facing dementia and possible compensation in exchange for the provision of their skills. Descriptive statistics are presented according to their frequencies and relative percentages (categorical variables), as well as by their mean, standard deviation and median (continuous variables). Logistic regression models were used to assess the factors associated with a favorable opinion towards win/win partnerships.

Results: The proportion of executives of health-related institutions with a positive opinion of partnership with caregivers is high: 74.7\% (95\% Cl: 64.8-83.1\%). Several types of potential partnerships have been identified between health institutions and caregivers. Areas in which certain activities have been identified as being able to be carried out by caregivers include governance, care, provision of services, accompaniment and support, training and research. Types of compensation for caregivers have also been highlighted.

Conclusion: This study shows that some areas activities of health facilities in the canton of Geneva could be the subject of win-win partnerships with caregivers of people with dementia. Positive view of health executives on partnership with caregivers is encouraging. In the future, innovative projects can emerge to meet the needs of each party.
\end{abstract}

Keywords: Caregivers, Partnership, Collaboration, Public heath

\section{Background}

In the context of a shortage of health personnel announced by the World Health Organization (WHO) (12.9 million by 2035) [1] and demographic changes that favour an increase in the incidence of chronic

\footnotetext{
* Correspondence: marie.leocadie@hesge.ch

${ }^{1}$ School of Health Sciences, HES-SO University of Applied Sciences and Arts Western Switzerland, Avenue de Champel 47, 1206 Geneva, CH, Switzerland ${ }^{3}$ University Paris 13, Sorbonne Paris Cite, Nursing Sciences Research chair, Laboratory Educations and Health Practices (LEPS), (EA 3412), UFR SMBH, F-93017 Bobigny, France

Full list of author information is available at the end of the article
}

diseases, such as Alzheimer's disease and other types of dementia, contribution of caregivers is essential.

Nevertheless, the overburdening of day-to-day activity causes caregivers to become exhausted, socially isolated and financially challenged. They also develop physical and psychological health problems related to "feeling of burden" [2-6]. The feeling of burden is defined as "all the physical, psychological, emotional, social and financial consequences borne by carers" [7]. Faced with this situation, caregivers' needs are based on information, training, recognition, coordination of care and mainly, respite $[8,9]$. 
Respite interventions have shown to provide support which is valued by caregivers. They are prevalent and varied. Nevertheless, caregivers do not systematically access respite devices because the services provided do not always answer to their needs. The dissatisfaction of caregivers is associated with many factors such as personal conflicts, organization, finances and their interaction with the health staff [10]. On the other hand, health institutions are commissioned by the political authorities to set up relevant and effective support mechanisms to help caregivers.

In order to provide different solutions adapted to caregivers' needs, it is necessary to collect data. A new paradigm of partnership is to be explored, so that a win/win partnership between caregivers and health institutions can answer both the caregivers needs as well as the needs of the health institutions. This could be a potential key to meeting their needs, including the need for respite.

This measure may also allow them to overcome difficulties related to lack of activity outside their caregiving. It could reduce the risk of isolation and feeling of burden, as well as increase their sense of competence, recognition and well-being.

Several researchers have already initiated research projects to promote partnerships between patients and healthrelated institutions. For example, the research team of the University of Montreal designed the "Montreal Model" [11] which integrates the individual skills of patients and/or their families within the different strata and domains of the health system (governance, care, health policy development, teaching, research). French research has put into practice the contribution of "teaching patients" to residents in general medicine who have recognized that this method has allowed for the acquisition of skills [12].

Moreover, the participation of actors in the health system will make it possible to improve the safety and quality of care as a whole. These multiple initiatives are supported by the fact that research has shown that scientific expertise must be nurtured through evidencebased medicine and knowledge-based medicine, among others, by patients and their families [13]. According to Yves Charpak in 2017, citizens who get involved with public health care issues as well as their own health care issues is based around how they position themselves. Citizens have duties but also rights that they want to assert when making decisions not only about public health issues but mostly their own health issues [14]. Other initiatives have been implemented in the United States [15], Great Britain [16] and France [17]. However, patient/family involvement initiatives based on the decisions and functioning of health-related institutions, remain anecdotal, according to Charpak [14]. Unlike other studies, the Hestia program conducted in Geneva, considers the need for caregivers to be acknowledged. In exchange for their competences, caregivers receive some respite free of charge which literature has shown to be their greatest need [18]. Indeed, according to Honneth in 2013, the recognition of society for services rendered is paramount for the psychological stability of citizens [19]. This is the case for family caregivers who, in 2014, thanks to their activities, saved Switzerland's healthcare system 3.4 billion CHF in costs. To enable the implementation of such a project, it is important to be able to answer several questions. The objectives of this study were to find out what percentages of executives in health-related institutions are favourable to establishing partnership projects with caregivers, as well as which activities related to the functioning of health-related institutions could be entrusted to caregivers in exchange for a free respite device.

\section{Methods}

Study design

This is a descriptive cross-sectional study of healthrelated institutions in the canton of Geneva. This study identifies activities that could be undertaken not only by staff within various health institutions but also with the caregivers themselves.

\section{Settings}

This study was conducted among various health institutions in the canton of Geneva: home care settings, nursing homes, hospitals, training centres and associations. Of the 71 health-related institutions that were invited to participate in our survey through postmail, a convenience sample of 21 centres replied positively. They are linked to the support of caregivers caring for patients confronted with Alzheimer's disease or other forms of dementia. Services not related to the population concerned were not included in the study.

\section{Study population}

In this study, the framework of health-related institutions linked with caregiving to patients confronted with Alzheimer's disease, or other forms of dementia, were included. Institutional staff who had no connection with the population concerned were not included in the study.

In addition to maximize the responses to our survey, a reminder was scheduled 15 days after the first mailing.

\section{Sample size}

In an arbitrary way and based on feasibility, the minimum percentage of participation desired was $50 \%$ of the 188 executives identified in the services participating in the study. Due to having no baseline study by which to calculate a standard deviation sample and appropriate confidence level, the Slovin formula was used for this study. After applying a margin of error of $5 \%$ and a 
correction factor, the minimum number of participants was determined to be 74 .

\section{Data sources/measurement}

This study was conducted with a survey which was inspired by the Montreal Model. We found areas of partnership within specific services of health-related institutions: activities related to organization, governance, care, service, accompaniment, support, training and research. The questionnaire consists of four (Additional file 1): the design of an anonymized identification number, sociodemographic data of the institution where the participants practice, description of the activities of the institution where the participants practice and perceptions of a possible partnership with caregivers in exchange for a respite device.

After the questionnaire was designed, three levels of testing were performed:

- First level: evaluation by experts. The survey was submitted for critical review with a pilot committee made up of experts in public health, medicine, education and support of caregivers. They assessed the relevance of the questions and their understanding.

- Second level: evaluation by 10 naive evaluators to evaluate the comprehension of the questionnaire.

- Third level: testing of the online procedure with 10 team leaders then utilising the statistical analysis tool.

After the survey was tested and the agreement of participating institutions was obtained, a link providing access to the survey was sent to the respondents. To ensure the anonymity of participants, a code was assigned. A response time of 15 days was granted. This time was needed for participants to discuss with their care teams and gather the opinions of each member. In addition, to maximize the return of the questionnaires, a reminder was scheduled 15 days after the first mailing.

\section{Variables}

The main outcome was to assess the percentage of cadres of health-related institutions who are in favour of a partnership project. The secondary outcome was to count in percentage the activities related to the functioning of health-related institutions that could be entrusted to caregivers in exchange for a respite device.

\section{Statistical methods}

First, categorical data was described in relation to frequencies and relative proportions overall as well as medical versus non-medical institutions. Continuous variables were be described by their mean, standard deviation (SD) and median overall and by medical versus non-medical institutions. Then, we compared specific answers between medical and non-medical institutions by applying a chi-squared test or Fischer's exact test according to the conditions of application. We presented associations by odds ratios and their $95 \%$ confidence intervals $(95 \% \mathrm{CI})$. All analyses were performed using STATA IC 15.0 software.

\section{Ethical consideration}

The research protocol was approved by the cantonal research ethics commission; the following number was assigned to the study: Req-2017-00211. A letter of information and consent form for participation in the study were sent by e-mail to the participants. The study modalities, possibilities of withdrawal and the guarantee of anonymity were stipulated. The return of the completed questionnaire constituted proof of the consent granted by the participant.

\section{Results \\ Description of institutions}

A total of 95 executives out of 188 from 21 health-related institutions in the canton of Geneva participated in this study: 2 initial training institutions, 1 cantonal hospital, 1 clinic, 12 social medical institutions, 3 home care institutions and 2 associations. Descriptive data identified the type, status, mission and activities (see Table 1).

Participants in home care facilities were the most likely to participate in the study (44.2\%). The institutions that participated in the study were mostly public $(89,5 \%)$ . Their missions were mainly focused on care and services to the population (82.1\%). The majority of activities identified in the field of organization and governance were linked to the ethical commissions $(60,6 \%)$ and to the various management fee $(56,4 \%)$. Regarding the supply of care, apart from activities related to the announcement of a diagnosis and respite/respite care, the other types of care are represented between 69 and $82 \%$. The most prevalent service offer in health-related institutions was patient support (64.2\%), followed by practical help (61.1\%) and meal delivery (56.8\%). Activities related to training were widely present in the various healthrelated institutions. Learning via theoretical courses was primarily present $(92.6 \%)$, followed by learning via practical lessons $(83.2 \%)$, then learning via practical training (68.4\%) followed by postgraduate and initial health training $(66.3,64.2 \%)$. Activities related to research were generally the least referenced. Accompaniment and support activities were also represented, with counselling of patients/families (64.2\%), coordination/orientation of care pathways $(56.8 \%)$, family respite $(56.8 \%)$, help with administrative procedures (57.9\%) and the organization of support sessions (43.2\%). 
Table 1 Description of institutions and their activities

\begin{tabular}{|c|c|}
\hline Variables & $N(\%)$ \\
\hline Type of institution & 95 \\
\hline Medical and social establishment & $12(12.6)$ \\
\hline Home care facility & $42(44.2)$ \\
\hline Training institute & $16(16.8)$ \\
\hline Patient and family association & $1(1.1)$ \\
\hline Hospital/clinic & $24(25.3)$ \\
\hline \multicolumn{2}{|l|}{ Status of the establishment } \\
\hline Public & $85(89.5)$ \\
\hline Private & $10(10.5)$ \\
\hline \multicolumn{2}{|l|}{ Main mission of the establishment } \\
\hline Education/training & $16(16.8)$ \\
\hline Care and services & $78(82.1)$ \\
\hline Support, advice and guidance & $1(1.1)$ \\
\hline Existing activities in the institutions & $N=94$ \\
\hline \multicolumn{2}{|l|}{$\begin{array}{l}\text { Activities related to organizational } \\
\text { matters }\end{array}$} \\
\hline Ethics committee & $57(60.6)$ \\
\hline Management fee & $53(56.4)$ \\
\hline $\begin{array}{l}\text { Commission to support a specific } \\
\text { population }\end{array}$ & $20(21.3)$ \\
\hline Welcoming newcomers/patients & $32(34.0)$ \\
\hline None & $2(2.1)$ \\
\hline Don't know & $8(8.5)$ \\
\hline Not applicable to my institution & $9(9.6)$ \\
\hline \multicolumn{2}{|l|}{ Activities related to the provision of care } \\
\hline Respite care & $50(52.6)$ \\
\hline Nursing care & $82(86.3)$ \\
\hline Care seminars & $72(75.8)$ \\
\hline Patient/family needs assessment & $76(80.0)$ \\
\hline $\begin{array}{l}\text { Implementation of patient/family } \\
\text { care plans }\end{array}$ & $75(79.0)$ \\
\hline Care coordination & $73(76.8)$ \\
\hline Analysis of complex care practice & $69(72.6)$ \\
\hline Announcement of a diagnosis & $23(24.2)$ \\
\hline $\begin{array}{l}\text { Health education/therapeutic } \\
\text { education }\end{array}$ & $69(72.6)$ \\
\hline None & $1(1.1)$ \\
\hline Don't know & $1(1.1)$ \\
\hline Not applicable to my institution & $8(8.4)$ \\
\hline \multicolumn{2}{|l|}{ Activities related to the service offer } \\
\hline Animations & $43(45.3)$ \\
\hline Socio-cultural activities & $29(30.5)$ \\
\hline Practical help & $58(61.1)$ \\
\hline Accompaniment (race ...) & $61(64.2)$ \\
\hline One-time call for help & $27(28.4)$ \\
\hline
\end{tabular}

Table 1 Description of institutions and their activities (Continued)

\begin{tabular}{ll}
\hline Variables & $N(\%)$ \\
\hline Meal provision & $54(56.8)$ \\
None & $5(5.3)$ \\
Don't know & $3(3.2)$ \\
Not applicable to my institution & $12(12.6)$ \\
Activities related to training & \\
Learning through theoretical education & $88(92.6)$ \\
Learning through practical teaching & $79(83.2)$ \\
Learning through teaching using & $29(30.5)$ \\
simulation & \\
Learning through practical internships & $65(68.4)$ \\
Learning through patients/expert & $20(21.1)$ \\
families & \\
Initial training of carers & $61(64.2)$ \\
Postgraduate training for carers & $63(66.3)$ \\
None & $0(0)$ \\
Don't know & $1(1.1)$ \\
Not applicable to my institution & $2(2.1)$ \\
Research activities & \\
Design of research protocols & $22(23.4)$ \\
Fundraising for the project & $7(7.5)$ \\
Request to the ethics committee & $39(41.5)$ \\
Research coordination sessions & $33(35.1)$ \\
Done & $40(42.6)$ \\
Not applipation of scientific days & $25(26.6)$ \\
Non & 26 (27.7) \\
\hline
\end{tabular}

Accompaniment and support activities

Support sessions

$41(43.2)$

Advice to patients/families

$61(64.2)$

Coordination/orientation of

$54(56.8)$

care pathways

Help with administrative 55 (57.9)

procedures

Family relief/respite

$54(56.8)$

None

$5(5.3)$

Don't know

$4(4.2)$

Not applicable to my institution

$9(9.5)$

Specific services for family caregivers

Currently, your institution offers services for caregivers

Among institutions providing

services for helping pockets,

average number

( \pm standard deviation, median) 
In addition, the participants listed secondary activities at their institution (see Table 1).

\section{Partnership agreement with caregivers in exchange for respite time}

The proportion of institutions with a positive opinion on partnership with caregivers was high: $74.7 \%$ (95\% CI: $64.8-83.1 \%)$.

\section{Type of partnership by type of institution}

The comparison between non-medical and medical facilities shows differences in various types of partnerships that could be offered to caregivers.

Medical institutions would be better able to offer more organizational and governance-type activities (ethics commissions and reception of newcomers or collaborators) than non-medical institutions. Medical facilities would potentially be able to offer more care activities (care seminars, patient/family needs assessments, care plans, coordination of care and health education) as well as activities in connection with service offers (entertainment, socio-cultural activities, practical help, support and meals) than non-medical establishments. Non-medical institutions would be better able to offer training activities (simulation-based courses, practical training, initial and postgraduate training, peer training) or research activities (co-construction of research protocols, creation of scientific days) than medical institutions (see Table 2). In their comments, the participants described other partnership ideas, such as the participation of caregivers in health homes, establishment of caregivers' cafes or permanence for caregivers. Their participation also planned to host families caring for patients with chronic diseases (see Table 2).

\section{Type of respite granted to caregivers in exchange for their skills}

A comparison of the two types of facilities indicated differences in home respite devices: non-medical facilities are more likely to offer day respite, while medical facilities may offer night respite and combined day/night respite. Overall, non-medical institutions could more frequently consider offering training in exchange for the skills of caregivers compared to medical facilities. Medical institutions may consider administrative support, psychological counselling or home-based meals more often than nonmedical institutions (see Table 3).

In the comments, the participants identified win-win partnership arrangements, but the situations described did not provide specific compensation for the needs of the caregiver (see Additional file 2).
Synthesis of the results (see Figs. 1, 2, 3, 4, 5 and 6)

Executives of health-related institutions in the canton of Geneva are in favour of win-win partnerships with caregivers. Partnership offers were linked to activities of institutions based on organization, governance, care, service, accompaniment, support, training and research in return for a free respite device.

There are differences in the partnership offers between medical institutions and non-medical institutions. Organizational and governance-type activities and care and service offerings are more likely to be offered by medical facilities. Non-medical institutions were better able than other institutions to offer partnerships around training and research. The most significant results $(p<0.001)$ were identified in partnerships between institutions related to healthcare and family caregivers when setting up patient/family care plans and accompanying other caregivers. On the other hand, with regard to health-related but nonmedicalised institutions, partnerships with very significant results $(p<0.001)$ were identified for activities related to initial and postgraduate training for caregivers and the creation of scientific study days.

The compensation offered in exchange for caregivers skills differs between the two types of establishments. Day respite could be offered by non-medical facilities, while night respite and combined day/night respite could be offered by medical facilities. In addition, medical and non-medical institutions could eventually offer other types of compensation.

\section{Discussion}

The purpose of this study was to identify activities related to the functioning of health-related institutions that could be entrusted to caregivers in exchange for a free respite device. In a changing national context regarding home care, as well as the growing involvement of caregivers, the results of this study are promising. They outline the possibility of win/win partnerships between health-related institutions and caregivers. The caregivers involved in this study were those caring for people with dementia. However, the partnerships can be generalised to other types of caregivers. Indeed, activities that can potentially be identified as part of a possible exchange with caregivers' skills are not specific to dementia. For example, a caregiver of a diabetic child can participate just as much as a caregiver of a person with dementia when designing a research protocol or training a peer.

The results show that both medical and non-medical institutions are positive about potential partnerships in areas such as organization, governance, care-related activities, service offerings, training, research, accompaniment and support activities. This goes in direction with the Montreal Model, which proposes patient/family 
Table 2 Type of partnership by type of institution: * survey variables

\begin{tabular}{|c|c|c|c|}
\hline \multirow[t]{2}{*}{ Type of partnership } & \multicolumn{2}{|l|}{ Type of institution } & \multirow[t]{2}{*}{$P$-value } \\
\hline & Non-medical, $n(\%)$ & Medical, $n(\%)$ & \\
\hline \multicolumn{4}{|c|}{ Proposals for organizational and governance activities* } \\
\hline Ethics committee & $3(17.7)$ & $44(56.4)$ & 0.004 \\
\hline Management fee & $2(11.8)$ & $4(5.1)$ & 0.308 \\
\hline Commission to support a specific population & $7(41.2)$ & $38(48.7)$ & 0.573 \\
\hline Welcoming newcomers/patients & $2(11.8)$ & $30(38.5)$ & 0.035 \\
\hline Welcoming new employees & $1(5.9)$ & $23(29.5)$ & 0.042 \\
\hline None & $9(52.9)$ & $11(14.1)$ & $<0.001$ \\
\hline \multicolumn{4}{|l|}{ Activities related to the provision of care* } \\
\hline Nursing care & $4(23.5)$ & $23(29.9)$ & 0.601 \\
\hline Care seminars & $2(11.8)$ & $44(57.1)$ & 0.001 \\
\hline Patient/family needs assessment & $3(17.7)$ & $59(76.6)$ & $<0.001$ \\
\hline Implementation of patient/family care plans & $4(23.5)$ & $52(67.5)$ & 0.001 \\
\hline Care coordination & $1(5.9)$ & $40(52.0)$ & 0.001 \\
\hline Analysis of complex care practice & $5(29.4)$ & $17(22.1)$ & 0.518 \\
\hline Announcement of a diagnosis & $3(17.7)$ & $18(23.4)$ & 0.608 \\
\hline Health education/therapeutic education & $6(35.3)$ & $50(64.9)$ & 0.024 \\
\hline None & $9(52.9)$ & $2(2.6)$ & $<0.001$ \\
\hline \multicolumn{4}{|l|}{ Activities related to the service offer* } \\
\hline Animations & $3(17.7)$ & $42(53.9)$ & 0.007 \\
\hline Socio-cultural & $1(5.9)$ & $38(48.7)$ & 0.001 \\
\hline Practical help & $2(11.8)$ & $37(47.4)$ & 0.007 \\
\hline Accompaniment (race...) & $3(17.7)$ & $54(69.3)$ & $<0.001$ \\
\hline One-time call for help & $3(17.7)$ & $25(32.1)$ & 0.238 \\
\hline Meal provision & $0(0)$ & $32(41.0)$ & 0.001 \\
\hline None & $10(58.8)$ & $9(11.5)$ & $<0.001$ \\
\hline \multicolumn{4}{|l|}{ Activities related to training* } \\
\hline Learning through theoretical education & $14(82.3)$ & $46(59.0)$ & 0.070 \\
\hline Learning through practical teaching & $13(76.5)$ & $46(59.0)$ & 0.178 \\
\hline Learning through teaching using simulation & $14(82.4)$ & $30(38.5)$ & 0.001 \\
\hline Learning through practical internships & $10(58.8)$ & $15(19.2)$ & 0.001 \\
\hline Initial training for carers & $13(76.5)$ & $24(30.8)$ & $<0.001$ \\
\hline Postgraduate training for carers & $11(64.7)$ & $16(20.5)$ & $<0.001$ \\
\hline Peer training & $10(58.8)$ & $21(26.9)$ & 0.011 \\
\hline None & $0(0)$ & $12(15.4)$ & 0.084 \\
\hline \multicolumn{4}{|l|}{ Research activities* } \\
\hline Co-construction of research protocols & $8(47.1)$ & $18(23.1)$ & 0.044 \\
\hline Fundraising for the project & $4(23.5)$ & $14(18.0)$ & 0.595 \\
\hline Request to the ethics committee & $4(23.5)$ & $13(16.7)$ & 0.504 \\
\hline Research coordination sessions & $4(23.5)$ & $11(14.1)$ & 0.334 \\
\hline Participation of scientific days & $13(76.5)$ & $15(19.2)$ & $<0.001$ \\
\hline None & $3(17.7)$ & $41(52.6)$ & 0.009 \\
\hline \multicolumn{4}{|l|}{ Accompaniment and support activities* } \\
\hline Support sessions & $9(52.9)$ & $49(62.8)$ & 0.449 \\
\hline
\end{tabular}


Table 2 Type of partnership by type of institution: * survey variables (Continued)

\begin{tabular}{llll}
\hline Type of partnership & Type of institution & \multicolumn{3}{c}{$P$-value } \\
\cline { 2 - 3 } & Non-medical, $n(\%)$ & $58(74.4)$ & 0.198 \\
\hline Advice to patients/families & $10(58.8)$ & $34(43.6)$ & 0.530 \\
Coordination/orientation of care pathways & $6(35.3)$ & $38(48.7)$ & 0.147 \\
Help with administrative procedures & $5(29.4)$ & $10(12.8)$ & 0.006 \\
None & $\mathbf{7 ( 4 1 . 2 )}$ & & \\
\hline
\end{tabular}

Table 3 Type of respite available to caregivers in exchange for their skills. * survey variables

\begin{tabular}{|c|c|c|c|}
\hline \multirow[t]{2}{*}{ Type of respite } & \multicolumn{2}{|l|}{ Type of institution } & \multirow[t]{2}{*}{$P$-value } \\
\hline & Non-medical, $n(\%)$ & Medical, $n(\%)$ & \\
\hline Favourable opinion regarding the provision of a free respite arrangement* & $14(82.4)$ & $56(71.8)$ & 0.370 \\
\hline \multicolumn{3}{|l|}{$\begin{array}{l}\text { Home respite plan that can be offered to family caregivers in exchange } \\
\text { for their skills** }\end{array}$} & \multirow[t]{5}{*}{$0.031^{a}$} \\
\hline Daytime respite & $8(47.1)$ & $14(18.0)$ & \\
\hline Night-time respite & $0(0)$ & $5(6.4)$ & \\
\hline Day and night respite & $4(23.5)$ & $42(53.9)$ & \\
\hline None & $5(29.4)$ & $17(21.8)$ & \\
\hline $\begin{array}{l}\text { Residential respite program UATR (temporary respite care unit) can be } \\
\text { offered to family caregivers in exchange for their skills* }\end{array}$ & $2(11.8)$ & $8(10.3)$ & $0.337^{\mathrm{a}}$ \\
\hline Daytime respite & $0(0)$ & $1(1.3)$ & \\
\hline Night-time respite & $9(52.9)$ & $56(71.8)$ & \\
\hline Day and night respite & $6(35.3)$ & $13(16.7)$ & \\
\hline \multicolumn{4}{|l|}{ None } \\
\hline \multicolumn{3}{|l|}{$\begin{array}{l}\text { Respite in the community can be offered to caregivers in exchange } \\
\text { for their skills* }\end{array}$} & \multirow[t]{5}{*}{$0.797^{\mathrm{a}}$} \\
\hline Daytime respite & $2(11.8)$ & $12(15.4)$ & \\
\hline Night-time respite & $0(0)$ & $1(1.3)$ & \\
\hline Day and night respite & $9(52.9)$ & $44(56.4)$ & \\
\hline None & $6(35.3)$ & $21(26.9)$ & \\
\hline \multicolumn{3}{|l|}{$\begin{array}{l}\text { Combined respite plan that can be offered to family caregivers in } \\
\text { exchange for their skills* }\end{array}$} & \multirow[t]{5}{*}{$0.271^{a}$} \\
\hline Daytime respite & $3(17.7)$ & $10(12.8)$ & \\
\hline Night-time respite & $0(0)$ & $0(0)$ & \\
\hline Day and night respite & $6(35.3)$ & $44(56.4)$ & \\
\hline None & $8(47.1)$ & $24(30.8)$ & \\
\hline $\begin{array}{l}\text { Possibility of offering other benefits than respite to family caregivers } \\
\text { in exchange for their skills* }\end{array}$ & $12(70.6)$ & $49(62.8)$ & 0.545 \\
\hline \multicolumn{4}{|l|}{ Other possible compensation* } \\
\hline Coordination of the care pathway & $4(23.5)$ & $17(24.6)$ & $0.599^{a}$ \\
\hline Training offer & $14(82.4)$ & $34(49.3)$ & 0.014 \\
\hline Administrative support & $2(11.8)$ & $28(40.6)$ & 0.026 \\
\hline Psychological follow-up & $3(17.7)$ & $30(43.5)$ & 0.050 \\
\hline Meals at home & $1(5.9)$ & $25(36.2)$ & 0.015 \\
\hline Remote monitoring subscription & $1(5.9)$ & $18(26.1)$ & $0.103^{a}$ \\
\hline None & $3(17.7)$ & $13(18.8)$ & $0.999^{a}$ \\
\hline Existence of a win/win partnership mechanism with caregivers in the institution* & $0(0)$ & $5(6.4)$ & $0.581^{a}$ \\
\hline
\end{tabular}




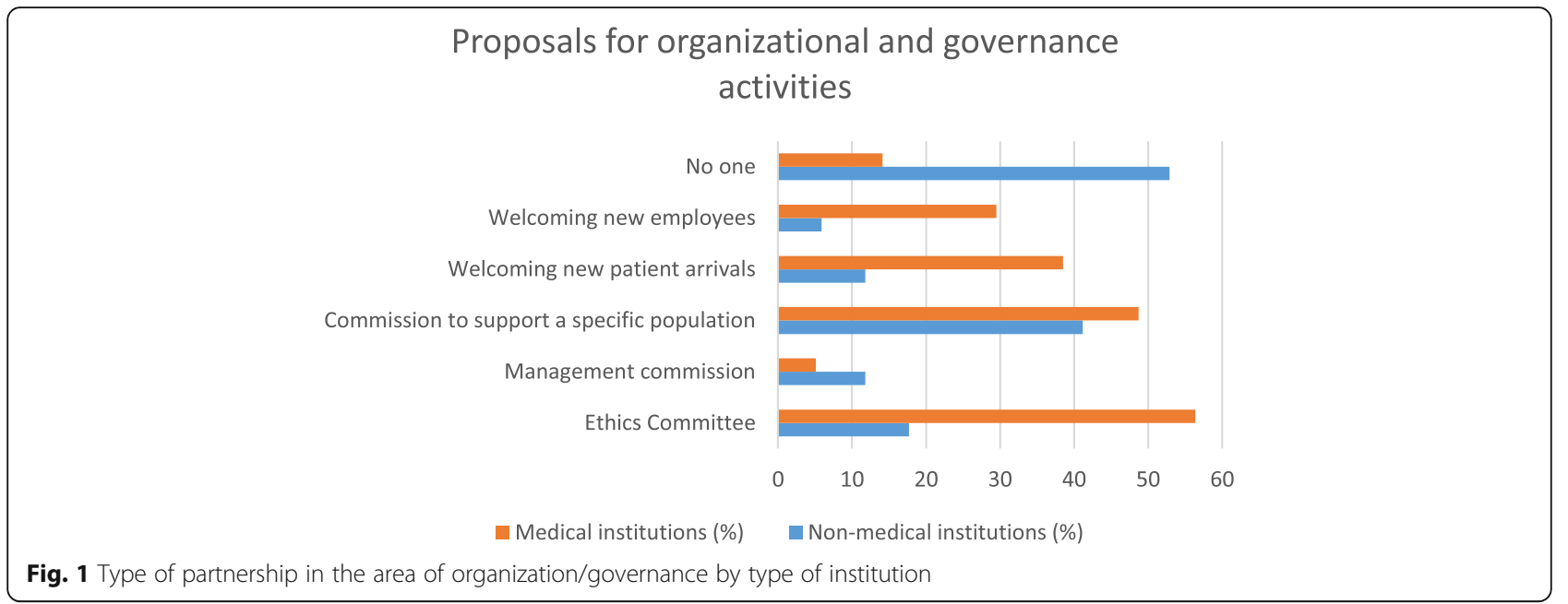

involvement in the various fields mentioned above [11]. Programs based on this model have shown positive results in improving quality of practices throughout the care process (reception, diagnosis announcement, care planning, etc.) as well as in collaborative practices and at the level of the institutional culture concerning partnership with the patient. They also highlighted an added value for the patient/family in improving a sense of social utility [20]. Regarding our study, the results highlight that the proportion of institutions with a favourable opinion towards partnership with caregivers is high: $74.7 \%$ (95\% CI: 64.8-83.1\%).

However, according to studies conducted by Carman et al. in 2013 [21] as well as the Center for Applied Pedagogy in Health Sciences at the University of Montreal in 2014 [22], several factors can influence the sustainability of a partnership program between caregivers, patients and their families: the characteristics of patients/relatives (values, attitudes, experiences, etc.); institutional culture and social norms that could influence the commitment of caregivers, the remuneration of various actors of the project and the training of patients/families as well as health professionals.

Joint training is envisaged by some universities to promote partnership between caregivers, patients and relatives $[20,21]$. The partnership is designed to share scientific knowledge of professionals and experiential knowledge of patients/families acquired during their life course with the disease [22].

The aim is to integrate patients/families within the health system as learners but also as bearers of experiential knowledge which allows health-related institutions to be learners as well [17]. The ultimate goal of this approach is to improve quality of life for the patient/family, as well as quality of care in coordination, safety, accessibility and efficiency [17]. Indeed, patients/families mobilize their expertise in relation to their experiences and not a scientific expertise held by various members within a health institution. However, when the latter are too far removed from the problems and needs of citizens, their actions tend to

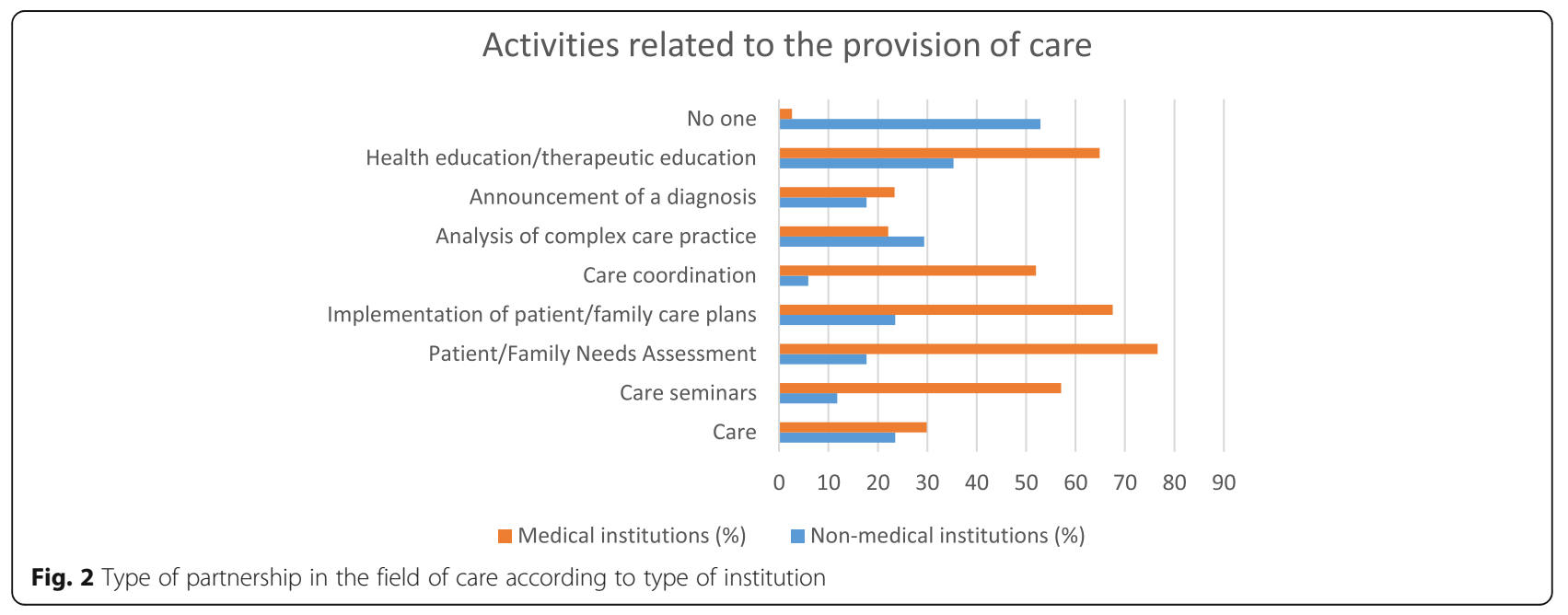




\section{Activities related to the service offer}

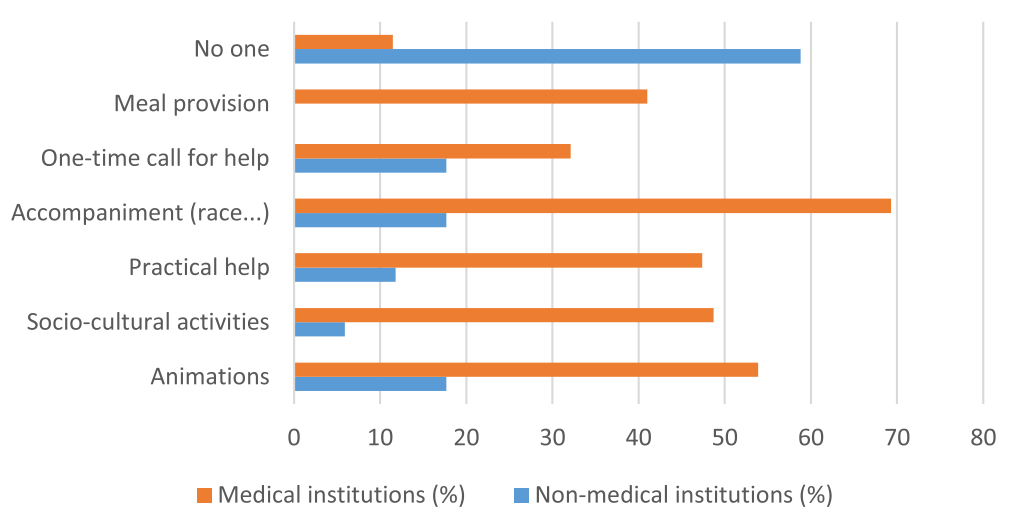

Fig. 3 Type of partnership in the field of service offering by type of institution

focus on their own issues [14]. For a decade, several initiatives have been proposed at the international level in the United States [15], Great Britain [16] and France [12, 17]. Patient/family involvement initiatives concerning decisions and functioning of health-related institutions remain, according to Charpak, anecdotal to needs [14]. As highlighted by some authors, lack of recognition can be a barrier to partnership [20, 21]. Indeed, according to Honneth and Rusch, the recognition of society for services rendered is paramount for the psychological stability of citizens [19]. This is the case for family caregivers who, in 2014, thanks to their activities, saved Switzerland's healthcare system 3.4 billion CHF in costs. As a result, the Hestia program is considering recognition through a no-cost response for the needs of caregivers. In this context, the results of this study were able to highlight examples of compensation envisaged to meet the recognition needs of caregivers. Indeed, this compensation has answered various needs which are abundantly identified in the literature [9]. Family caregivers essentially need respite, training, information, recognition, financial aid as well as to fight against social isolation $[8,9]$. The proposed compensation forms mainly involve the provision of training, administrative support, organizational support, psychological follow-up and a free respite device. Between the needs identified in the literature and the compensation offers envisaged in this study, we can see responses to needs. In fact, taking the example of respite, the results show high interest in proposing a free respite device in exchange for the skills of caregivers $(73.7 \%$; $95 \% \mathrm{CI}$ : 63.6-82.2\%). The different types of respite offered respond to an existing need for respite both day and night.

However, it is important to stay vigilant towards the vulnerability of caregivers. They are among the main actors of the health system. They help to promote home support of their loved ones. Their involvement is strong, but in the long run, can be exhausting for some. It favours the onset of feeling of burden with psychological and physical exhaustion. This state is accentuated by social isolation, lack of recognition and lack of respite.

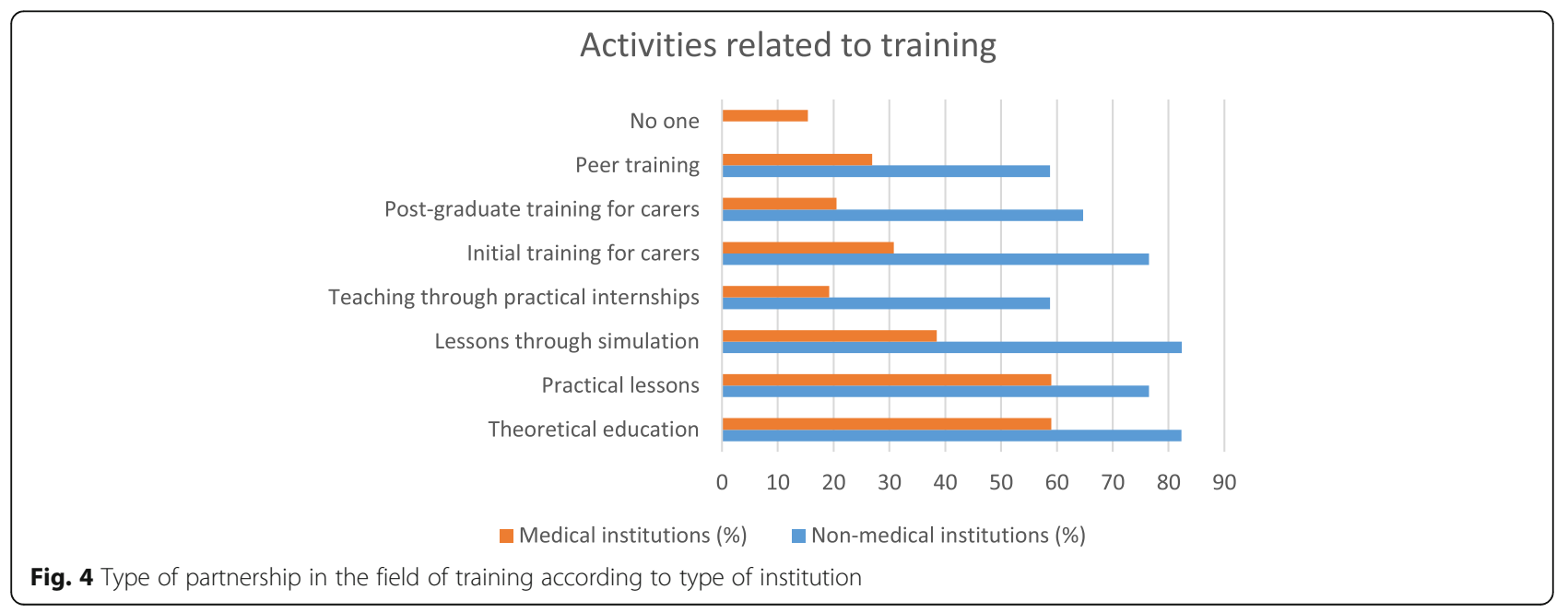




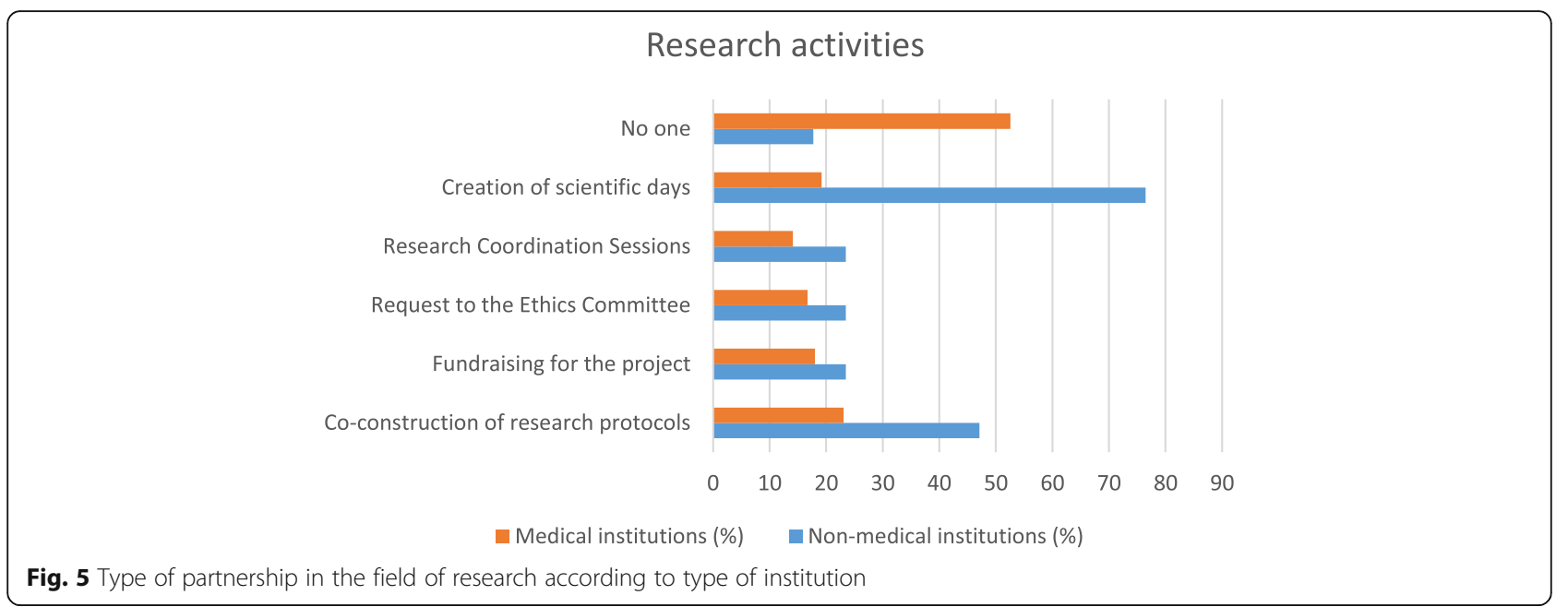

To combat this, according to Meleis in 2010, it is essential to accompany the caregiver in his or her role change, particularly in the acquisition of knowledge and skills not yet mastered; in his or her ability to adapt; in the sense given to his actions; in feeling connected; in constant interaction; in his or her experience with illness; in developing his or her confidence and in becoming aware of his or her new role [23]. As part of a win/win partnership project, it is hypothesized that recognition as a direct response to caregivers' own needs can only improve their transition. Given the risk of burnout, it is therefore important to think about projects which take into account the wishes and availability of caregivers. This activity must in no case be obligatory for caregivers; it must be voluntary and respond in a systemic and unitary way to their needs and expectations.

\section{Limitations and interests of the study}

The strength of this study is in the local evaluation of potential partnerships that can provide a response to local policies that are, among other things, focused so far on the support of caregivers [24]. It will allow for the possibility of win/win partnerships. It focused on the population facing dementia but the results are transferable to other populations. This study had some limitations. The survey was conducted with health-related institutions; however, it could also have been carried out with institutions related to the social environment or industry. Indeed, the issues of caregivers also fall within these two areas. The partnership proposals could have been even richer and more diversified. In addition, the survey used in this study aimed to sound out the proportion of positive opinions for a partnership between health-related institutions and caregivers in the canton of Geneva. In addition, the goal was also to identify local health-related activities that could be potential partners. Such a survey did not exist. It was therefore created specifically for the study. The tests performed to verify the validity of this survey correspond to the content validity tests described by Fortin M. F in 2006. The psychometric tests to verify the fidelity of this

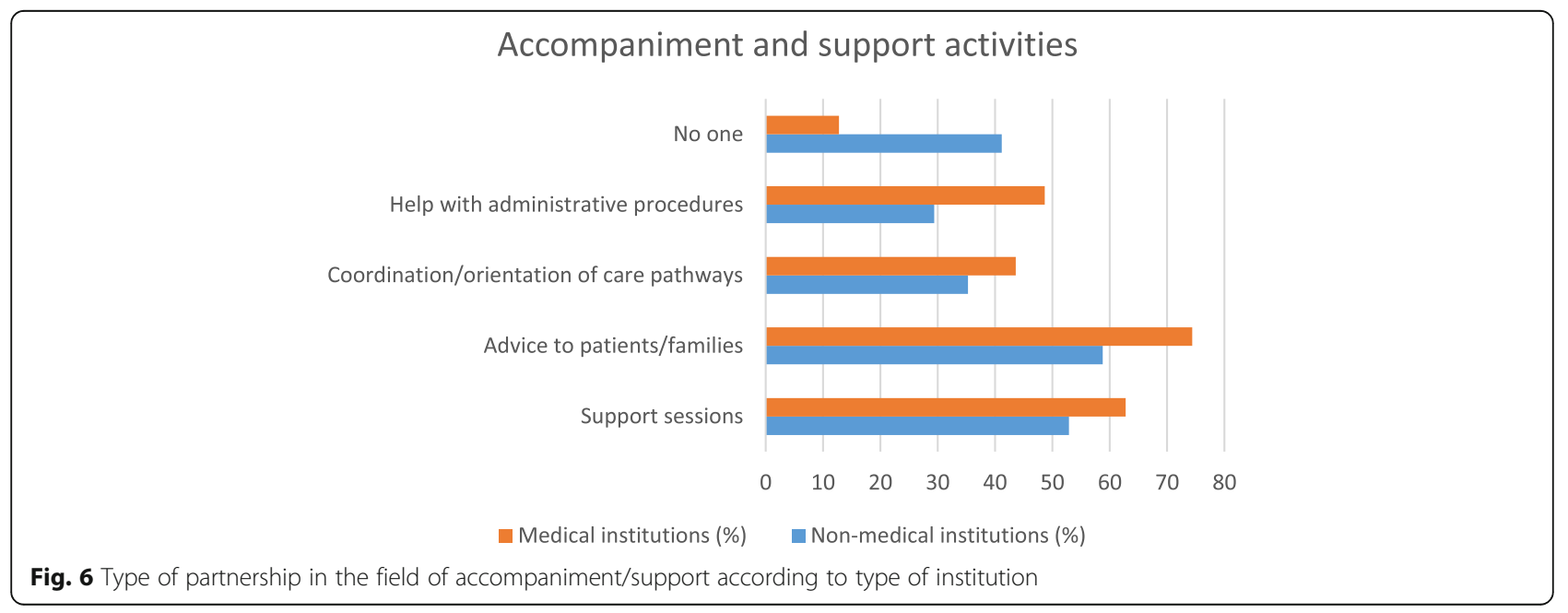


instrument have not been performed and represent a limit to this study.

\section{Conclusion}

This study shows that the senior staff of health-related institutions in the canton of Geneva are interested in establishing win/win partnerships with caregivers of people facing dementia. These positive results encourage new partnerships. In the future, innovative projects can emerge to meet the needs of each party. The caregiver's position can evolve to a position that will give him or her the right to use his or her skills in institutions related to health. Caregivers will be considered even more as actors of public utility. The care will not only be thought of as being centred on the patient's/family's health concerns and problems but also in partnership with the patient/family. This is a paradigm shift that has already evolved across the Atlantic but must make its mark at the European level.

\section{Additional files}

Additional file 1: Questionnaire, potential partnerships between healthrelated institutions and caregivers. (DOCX $94 \mathrm{~kb}$ )

Additional file 2: Participants' answers to the open-ended questions of the questionnaire. (DOCX $46 \mathrm{~kb}$ )

\section{Acknowledgements}

The researchers would like to thank the various institutions that participated in the study. We would also like to acknowledge Ms. Gayet-Ageron Angèle who helped in the statistical treatment of the study as well as her reading of this article.

\section{Authors' contributions}

MCL and MTR initiated and developed the strategy for this study. MCL performed the data collection. MCL and MTR contributed to the data synthesis. MCL wrote the first version of the manuscript. MCL wrote the article. MTR, LH provided constructive criticism during the writing of the article. All authors have read and approved the final version of this article.

\section{Funding}

The researchers received no funding

\section{Availability of data and materials}

All data used and/or analysed in the current study are available from the corresponding author upon reasonable request.

\section{Ethics approval and consent to participate}

The research protocol was approved by the cantonal research ethics commission. The following number was assigned to the study: Req-2017-00211. The ethics committee approved implicit consent by returning the participants' questionnaire.

\section{Consent for publication}

Not applicable.

\section{Competing interests}

The authors declare that they have no competing interests.

\section{Author details}

${ }^{1}$ School of Health Sciences, HES-SO University of Applied Sciences and Arts Western Switzerland, Avenue de Champel 47, 1206 Geneva, CH, Switzerland. ${ }^{2}$ Emérites professor for nursing, Montréal University, Québec, Canada.
${ }^{3}$ University Paris 13, Sorbonne Paris Cite, Nursing Sciences Research chair, Laboratory Educations and Health Practices (LEPS), (EA 3412), UFR SMBH, F-93017 Bobigny, France. ${ }^{4}$ APHP, Nursing Sciences Research chair Paris, Paris, France.

Received: 15 February 2019 Accepted: 20 May 2019

Published online: 07 June 2019

\section{References}

1. World Health Organization. A universal truth: no health without a workforce 2014. https://www.who.int/workforcealliance/knowledge/resources/GHWAa_universal_truth_report.pdf?ua=1. Accessed 15 Feb 2019.

2. Akkerman RL, Ostwald SK. Reducing anxiety in Alzheimer's disease family caregivers: the effectiveness of a nine-week cognitive-behavioral intervention. Am J of Alzheimers Dis Other Demen. 2004;19(2):117-23.

3. Brousseau Y, Ouellet N. Description de la fatigue chez les proches aidants d'un parent atteint de troubles cognitifs. L'Infirmière Clinicienne 2010;7(1):24-32

4. Ferrara M, Langiano E, Di Brango T, De Vito E, Di Cioccio L, Bauco C. Prevalence of stress, anxiety and depression in with Alzheimer caregivers. Health Qual Life Outcomes. 2008;6:93

5. Schulz R, Obrien AT, Bookwala J, Fleissner K. Psychiatric and physica morbidity effects of dementia caregiving - prevalence, correlates, and causes. Gerontologist. 1995;35(6):771-91.

6. Zarit SH, Reever KE, Bachpeterson J. Relatives of the impaired elderly correlates of feelings of burden. Gerontologist. 1980:20(6):649-55.

7. Bocquet HA. S. Le "burden", un indicateur spécifique pour les aidants familiaux. Gérontologie et Société. 1999:89:155-66.

8. Pin S, Spini D, Pierrig-Chiello P. Rapport de recherche sur les proches aidants : étude sur les proches aidants et les professionnels de l'institution genevoise de maintien à domicile dans le canton de Genvève. AGEneva Care; 2015. https://www.ge.ch/document/proches-aidants-etudeagenevacare/telecharger. Accessed 15 Feb 2019.

9. McCabe M, You E, Tatangelo G. Hearing their voice: a systematic review of dementia family caregivers' needs. Gerontologist. 2016;56(5):70-88.

10. Leocadie MC, Roy MH, Rothan-Tondeur M. Barriers and enablers in the use of respite interventions by caregivers of people with dementia: an integrative review. Arch Public Health. 2018;76:72 open access.

11. Pomey MP, Luigi F, Karazivan P, Dumez V, Lebel P, Vanier MC, et al. Le "Montreal Model" : Enjeux du partenariat relationnel entre patients et professionnels de la santé. Revue Santé Publique. 2015;51:41-50.

12. Aires MJ, Gagnayre R, Gross O, Khau CA, Haghighi S, Mercier A, et al. The patient teacher in general practice training: perspectives of residents. J Patient Exp. 2018:2:1-9.

13. Glasby J, Beresford P. Who knows best? Evidence-based practice and the service user contribution. Crit Soc Policy. 2006;26:268-84.

14. Charpak Y. La participation des citoyens à la décision en matière de santé et sur leur propre santé : enjeux, pièges, risques et innovations. Revues Réalités Industrielles. 2017;05:60-3.

15. Lorig KR, Sobel DS, Stewart AL, Bandura A, Ritter $P$, et al. Evidence suggesting that a chronic disease self-management program can improve health status while reducing hospitalization: a randomized trial. Med Care. 1999:37(2):5-14.

16. National health service. The expert patient: a new approach to chronic disease management for the 21st century. London: Publisher; 2001.

17. Flora L. Le patient formateur : élaboration théorique et pratique d'un nouveau métier de la santé. Paris: Université Vincennes-Saint-Denis - Paris 8; 2012

18. McNally S, Ben-Shlomo Y, Newman S. The effects of respite care on informal carers' well-being: a systematic review. Disabil Rehabil. 1999;21(1):1-14.

19. Honneth A, Rusch P. La lutte pour la reconnaissance. Paris: Folio Essais; 2013.

20. Centre de Pédagogie Appliquée aux Sciences de la Santé de l'Université de Montréal C. Programme patenaire de soins. Rapport d'étape (2011-2013) et perspective. Montréal: Université de Montréal, Direction Collaboration et Partenariat Patient; 2014

21. Carman KL, Dardess P, Maurer M, Sofaer S, Adams K, Bechtel C, et al. Patient and family engagement: a framework for understanding the elements and developing interventions and policies. Health Affair. 2013;32(2):223-31.

22. Centre de pédagogie appliquée aux sciences de la santé de l'université de Montréal. Guide d'implantation du partenariat de soins et de services, vers une collaboration optimale entre intervenants et avec le patient. 2014. 
http://ena.ruis.umontreal.ca/pluginfile.php/256/coursecat/description/Guide_ implantation1.1.pdf. Accessed 15 Feb 2019.

23. Meleis Al. Transition theory. Middle-range and situation-specific theories in nursing research and practice. New York. New York: Springer Publishing Company; 2010

24. Commission consultative pour le soutien des proches aidants actifs. à domicile. Programme de soutien aux proches aidants du canton de Geneve 2017/2020. Genève: Publisher; 2017.

\section{Publisher's Note}

Springer Nature remains neutral with regard to jurisdictional claims in published maps and institutional affiliations.

Ready to submit your research? Choose BMC and benefit from:

- fast, convenient online submission

- thorough peer review by experienced researchers in your field

- rapid publication on acceptance

- support for research data, including large and complex data types

- gold Open Access which fosters wider collaboration and increased citations

- maximum visibility for your research: over $100 \mathrm{M}$ website views per year

At $\mathrm{BMC}$, research is always in progress.

Learn more biomedcentral.com/submissions 